\title{
Health care provider choice and utilization among the elderly in a state in Brazil: a structural model
}

\author{
Antonio M. Bos ${ }^{1}$
}

Suggested citation

Bos AM. Health care provider choice and utilization among the elderly in a state in Brazil: a structural model. Rev Panam Salud Publica. 2007;22(1):41-50.

ABSTRACT Objectives. Current demographic trends point to the need for understanding the health challenges facing the elderly in Latin America today. This study assessed whether health care provider choice and household income impact utilization and health among the elderly in Brazil. Methods. Using a sample taken in 1995 in southern Brazil, a structural model was used to estimate the parameters of a function that represents the choice of health care provider, controlled for health care services utilization and a health production function. The dependent variable for the production function was self-assessed health. These two functions were structurally linked by introducing the probability of choosing a private over a public provider in the health production function as an added explanatory variable. With this structural linkage, the production function assessed how much the selection of a public versus a private provider affects health, while controlling for the possibility that individuals with poorer health have a tendency to prefer one or other health care provider.

Results. Health care services utilization by the elderly was constrained by two factors: the number of providers at the municipality level and household income. The elderly who live in municipalities with a greater number of public, outpatient clinics and providers were more likely to use the public system. Patients who used the public health care system had lower selfassessed health status than those using the private system. This result is valid even after controlling for demographic variables and morbidity.

Conclusions. Brazil's public health system does not adequately provide for the health needs of the elderly population. Policy recommendations include further investments in the public health care infrastructure, full implementation of the National Plan for Elderly Health, and developing new programs for effective geriatric consultations at the primary care level.

Key words Health services for the aged, health transition, public health practice, geriatrics, Brazil.

Like most of Latin America, Brazil is experiencing a significant demo-

\footnotetext{
1 Tusculum College, Greeneville, Tennessee and Department of International Health, Johns Hopkins School of Public Health, Baltimore, Maryland. Send correspondence to: Antonio M. Bos, Tusculum College, 60 Shiloh Road, Greeneville, TN 37743, USA; telephone: (423) 636-7300; e-mail: abos@tusculum.edu.
}

graphic transition. The percentage of the population over 60 years of age is expected to grow from $8.6 \%$ to $18.5 \%$ in the 30 years from 2000 to 2030 (1). Along with the rest of the population, the elderly are subject to the benefits and challenges of the Sistema Único de Saúde (SUS), Brazil's public health care system. Although SUS offers universal access and no-cost services, it suffers from a lack of adequate funding (2). SUS deficiencies are evident in both the quality and quantity of health care services offered. In terms of quality, deficiencies may be witnessed in short consultations, improper diag- 
nostic procedures, and inadequate explanations/advice for patients (3). In terms of quantity, deficiencies are found in the limited number of ambulatory clinics, understaffing, and shortages of both hospital beds and prescription drugs. These shortcomings generate long waiting-periods for office visits and medical procedures (3). Some of the elderly have responded by seeking private health care providers (4), and paying for services directly or through a private health insurance plan.

In Brazil, the unique health care needs of the aging population have only recently been brought to the forefront of public health care $(2,5)$. Therefore, it is highly likely that an elderly Brazilian will be attended by a provider unskilled in proper diagnosis and treatment of geriatric issues (6). The National Plan for Elderly Health, just introduced in 1999, focuses on three levels of care, all of which have met with challenges (7). First, at the preventive health care level, the "Health Program for Families" program, reaches a sizeable part of the population, but lacks training for providers needed for elderly health care (8). Second, at the primary care level, the Plan aims for a "geriatric consultation," but the extent of these consultations is also very limited. Third, at the hospital care level, the goal is to designate certain hospitals as "Resource Center for Elderly Health." Hospitals with this designation have the technical capabilities, medical equipment, and staff appropriate for geriatric health care; however, in reality, there are very few of them-only 74 such hospitals in the whole country. In addition, the program's impact has not been adequately measured.

Elderly health is determined by a combination of social, economic, and policy factors; physiological changes caused by aging; and the consequences of lifelong behavioral choices. The present study uses a structural model to analyze the health challenges faced by the elderly in Brazil. The model specifies a causal pathway to health, and is uniquely appropriate for analyzing the impact of public health care policies. Two specific issues are the focus of whether or not they affect the utilization of health care services and health outcomes: the number of health care resources available and choice of a public versus a private health care provider.

In the context of Brazil, the local availability of health care resources should have an impact on their utilization. Once an elderly individual recognizes the need for health care, seeking and receiving the necessary services depends on: the availability and appropriateness of the local health care resources, the financial situation of the individual, and the status of his/her health insurance. A decision that will need to be made is whether to chose a private or a public health care provider, a choice that depends-in addition to other factors-on the relative cost of these two options. Private providers require payment, either directly or via health insurance premiums, and although public providers do not charge a fee, other costs may be implied, such as longer waiting periods and transportation.

Given the aforementioned deficiencies in public health care services for the elderly, seniors may select a private provider because their needs will be better met (3). Elderly patients who chose a private provider should achieve better health outcomes than those who rely on the public system, after controlling for other healthrelated variables. On the other hand, the use of private providers involves high financial costs and increases the risk that a substantial portion of the household budget will go toward health care. With "catastrophic" health care expenses defined as $40 \%$ of household income, Brazil has the highest proportion of households with catastrophic health care expenditures $(10.3 \%)$ in Latin America (9). Another study $^{2}$ not only verified that choosing

\footnotetext{
2 Bos AM, Waters H. Financial protection in health in Brazil: A Heckman probit estimation of the probability of catastrophic health expenditures. Fifth World Congress of the International Health Economics Association. Barcelona, Spain; July 1013, 2005.
}

a private, rather than a public, provider is strongly associated with catastrophic levels of health expenditures, but that this association occurs even in households with health insurance coverage. The same study found that households with one or more elderly individuals are more likely to have catastrophic health care expenditures than households without elderly.

All the issues discussed above are worth evaluating in order to direct health care policy. Important questions to consider are: What are the constraints to health care utilization by the elderly? What are the determining factors when choosing between a public and a private provider? What are the health consequences of using a public, rather than a private provider, considering that the use of a private provider might expose the elderly and their households to substantial financial risk? Answers to these questions are relevant, not just in Brazil, but in other middle-income countries of Latin America, especially given their similar demographics and public health systems, in general.

\section{MATERIALS AND METHODS}

\section{Structural model}

The structural model used in this study controlled the endogeneity between health care provider choice and health outcomes. In its most general form, it is defined by a health production function and a health input demand function (10-12):

$$
\begin{aligned}
& \text { health production function: } \\
& \quad H=H(H I, X) \\
& \text { health input demand function: } \\
& H I=H I(X, Y, P)
\end{aligned}
$$

In the two functions, $H$ is the health status or outcome, $H I$ is a vector of health inputs, $X$ is a vector of individual and household factors that influence health, $Y$ is a measure of income, and $P$ is a vector of prices. The health input demand function states that an elderly individual selects health inputs 
based on personal preferences, financial resources, and cost. The specific health input considered in this study is the choice between public and private health care providers, including the decision to seek or not to seek care. The health production function assesses how health inputs determine health status, moderated by individual and household factors.

The benefit of a structural model is that it explicitly considers the selection of health care provider as an endogenous variable within the model. If the selection variable were entered directly into the health production function, the measured effect would be a function of a two-way causal relationship. On one hand, health status, as an outcome, might be caused by the selection of health care provider. On the other hand, the choice of provider might be caused by the current health status. The structural model attempts to distinguish between these two possibilities. The health input demand function assesses whether the choice of health care provider is caused by current health status. In other words, it assesses whether elderly individuals with poorer health status tend to choose pubic or private health care providers. In the present model, this is done indirectly by the introduction of individual and household factors that impact health status. Once this estimation is performed, the expected probability of the health care provider choice can be generated and this expected probability can be entered into the health production function. The impact that the expected probability will have on health will be primarily due to the choice of health care provider generating health outcomes as, again, the inverse relationship has been accounted for by the health input demand function.

\section{Data sources}

The present work used the Multidimensional Study of the Conditions of Life of the Elderly database in the state of Rio Grande do Sul, Brazil (13). The target population of this 1995, cross-sectional study was state residents of either sex, at least 60 years of age who were urban and noninstitutionalized. The sample size was 7920 individuals from 79 municipalities and data were collected through a 121question survey. This research also used data for specific municipalities, as described below, gathered from the "Research on Medical and Sanitary Assistance" (14).

Rio Grande do Sul is the southernmost state in Brazil, with about 10.2 million inhabitants in 2000. It is slightly more advanced in the demographic transition than the rest of Brazil, with a higher proportion of elderly: $10.5 \%$ of the state population as opposed to $8.9 \%$ for the country as a whole (1). The quantity of health care resources in this state and the whole country are similar. The number of ambulatory clinics is almost identical, 0.29 per 1000 persons. The number of physicians is also very similar-4.4 per 1000 as opposed to 4.1 per 1000 for the whole country (15).

\section{Dependent variable: self-assessed health}

For the dependent variable "selfassessed health," the survey question was phrased as "In general, how would you say your health is?" (Em geral diria que sua saúde é... ?) and the five possible responses were "excellent, good, fair, poor, and very poor" (ótima, boa, regular, ruim, muito ruim). The distribution of this variable for the sample was $9 \%$ excellent, $27 \%$ good, $50 \%$ fair, $7 \%$ poor, and $8 \%$ very poor. Women reporting slightly poorer health than men. This distribution and pattern are similar to the country as whole (15) and to the city of São Paulo, based on the Survey on Health, Wellbeing, and Aging in Latin America and the Caribbean (2).

Self-assessed health is a subjective measure, but several studies have shown it to be a good proxy for health status-including chronic and acute conditions-and is highly correlated with mortality, morbidity, and health care utilization $(16,17)$. Still, it is a single and subjective measurement of a complex phenomenon. Concerns about this indicator include reliability (18), validity (19), and bias due to financial incentives (20).

The reliability and validity of the self-assessed health variable were estimated with the help of other health indicators from the survey analyzed in this study. The main results of these analyses are presented here, but detailed accounts are available from the author. A morbidity scale was calculated based on the number of specific health conditions for which the survey participants had been treated during the 6 months prior to the study. The results show self-assessed health to be related to morbidity-those reporting better self-assessed health also reported fewer health conditions, and those with poorer self-assessed health also reported more health conditions. In addition, a scale for activities-ofdaily-living (ADL) was calculated based on the number of activities with which the elderly in the sample needed assistance. The results show that self-assessed health and ADL are closely related. Persons reporting better, self-assessed health also report fewer activities for which they required assistance, while those with poorer self-assessed health reported the need for more assistance.

Finally, the response to a health question requiring self-assessment might be biased by financial incentives, such as disability insurance benefits, and/or by social stigmas, such as retirement due to poor health, rather than the less-accepted desire for leisure (20). This particular bias is not important in the study sample since only $11 \%$ retired for health reasons. In addition, retirement for health reasons was not directly related to current health, measured either by selfassessed health or by the number of chronic conditions under treatment.

Another concern regarding the validity of self-assessed health is whether income affects how different levels of "true" health are translated into "perceived" health. To measure the influence of income on this variable, the study looked at whether the 
thresholds in the ordered regression models were sensitive to income level (21). When survey respondents are asked to place their health status on a scale-excellent, good, fair, poor, very poor-each makes this placement based on whether their perceived health status is above or below unspecified thresholds. For instance, if the health is perceived to be slightly worse than what the responder considers the threshold for "excellent health," he/she might answer this question by marking "good health."

The regression process estimates the values for these thresholds, with a favorable result being that these values do not vary by the respondent's income level. In such a case, richer and poorer respondents would have similar standards for what constitutes "excellent health," as well as for the other possible levels of health. An important implication is that there is a stronger justification for, for instance, a positive relationship between income and selfassessed health, that is, that richer individuals have "better health", instead of differences in standards. To test this, the sample was divided at the median income into lower- and upper-income subsamples, and the ordered regression was run for each subsample. The thresholds between the ordered categories for the poorer and richer subsamples were compared. This test was performed in the health production function regression, described below. No significant difference in cut points between richer and poorer respondents was found.

\section{Health care utilization}

According to the completed surveys, in the state of Rio Grande do Sul, $72 \%$ of the elderly sought and received health care services (a consultation with a doctor) at least once during the 6 months prior to the study. Of these, $55 \%$ used a public (SUS) provider, while $45 \%$ used a private provider. The survey questions regarding utilization addressed the place of firstcontact with health care services (primary care). The most common public providers were public ambulatory clinics and doctor's offices that provide services through SUS. In this paper, the term "ambulatory clinic" refers to outpatient facilities (no overnight admission/care). The most common private providers were independent, private doctor's offices.

\section{Health care costs}

As part of Brazil's public health care system, government-owned ambulatory clinics are financed by taxpayers and do not charge user-fees; and private ambulatory clinics and physicians that provide services within the public health system are reimbursed by the government. Therefore, the use of the public system implies zero direct monetary costs to the patient although the nonmonetary costs might be substantial, as previously mentioned (22). Although this study did not collect data on these issues, a good proxy for nonmonetary costs is the number of public ambulatory clinics, per capita, at the municipality level. It is expected that, on average, waiting times and distances are lower in municipalities with higher numbers of public providers per capita. In the state of Rio Grande do Sul, public ambulatory clinics are targeted to the smaller and poorer municipalities since the correlation of this variable with municipality population and per capita municipality income are negative, -0.374 and -0.411 , respectively.

As noted above, when private ambulatory clinics or physicians provide services through the public health system, they are reimbursed by the government and do not charge patients. However, not all private providers are within the public system full time. In these cases, when a patient seeks care from these providers outside the public system, there is a charge for services, either directly or through private health insurance. The survey did not collect information on fees charged by private providers. A good proxy for these prices, at the municipality level, is the number of private physicians per capita, as physicians would tend to gravitate toward municipalities in which they can charge higher prices. In other words, the quantity of private physicians supplied corresponds with higher prices. This possibility, is supported by the fact that there are more private physicians per capita in richer municipalities. The correlation with average municipality income is 0.66 ; and in larger municipalities, it is 0.63 . Notice that, whereas these correlations are positive, the correlations for public ambulatory clinics were negative, suggesting that private providers are reacting to market demand, whereas public providers are not. This interpretation is similar to that of another study (23) where the availability of health care services, as a measure of quantity supplied, was one factor used to estimate the rates charged by private doctors. However, it is not possible to rule out the inverse possibility, that a higher supply of physicians in larger and richer municipalities would lead to lower prices in these areas. In this case, this price proxy will yield a positive sign in the health input demand estimation.

\section{Independent variables}

Table 1 defines the explanatory variables used in the analysis and presents some basic descriptions. The demographic variables are those most likely to affect health and health behavior, as extensively shown in the literature (24).

\section{Data imputation}

Several responders answered, "I do not know" for the question on household income: 1037 cases $(13 \%$ of the usable sample). A descriptive analysis shows that the elderly who are unaware of the family's income, tend to be widowed, older women, living with their children. This suggests that if these cases had been eliminated from the usable sample, the results would have been seriously biased.

Data imputation was based on the predicted values from an ordinary 
TABLE 1. Independent variables analyzed to determine elderly choice of health care provider and utilization, state of Rio Grande do Sul, Brazil, 1995

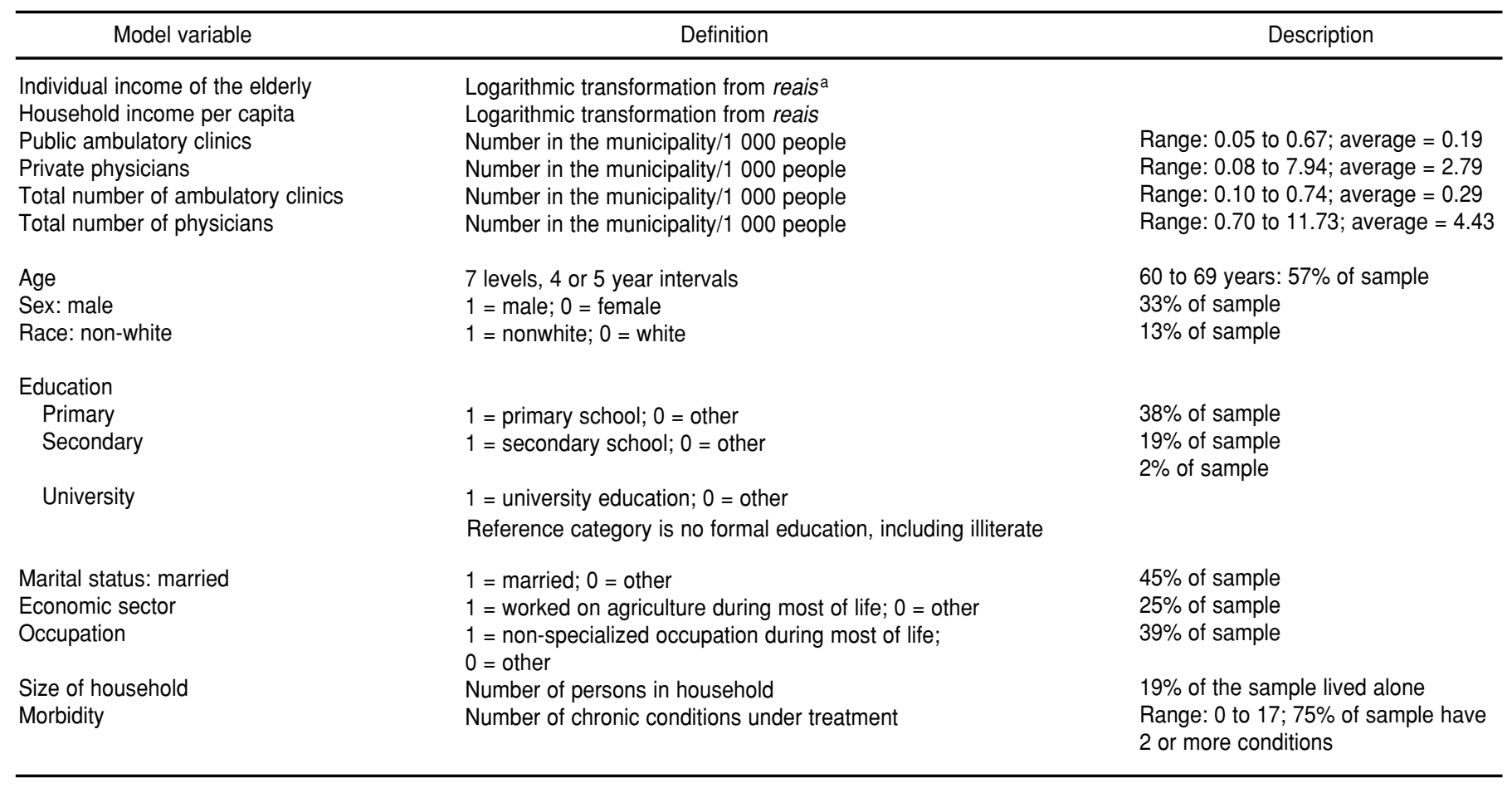

a Currency of Brazil.

least-square regression (25). The explanatory variables for this regression were the full set of demographic variables described in Table 1, plus the elderly individual's household income, and the average, per capita, municipality income. To introduce randomness to these values, the stochastic prediction was calculated by adding to the deterministic, predicted value, the expression $(M S E)^{1 / 2}{ }^{*} \mathrm{Z}$, where MSE is the mean square error of the regression and $Z$ is an independent, normally-distributed, random variable with a mean of 0 and a standard deviation equal to $1(26,27)$. By generating different random variables, five imputations for household income were created, and although the results did not differ greatly, the imputation that yielded the least number of zero values for household income was chosen for the regression analysis presented. All regressions with household income were run with the different imputations and the changes in the results were insignificant. To assess whether the imputation introduced biases, a variable was inserted into the regressions, to show whether or not the observation had an imputed value for household income.

\section{Econometric specifications}

The choice between private and public providers was estimated with a probit regression, and the decision on seeking health care was incorporated into the model as a Heckman selection correction. Under this model, the choice of providers is only observed if health care is sought. If the correlation between these two decisions were not zero, a simple probit regression applied to the choice of providers would yield biased results.

As in other probit models, it is assumed that there is an underlying relationship (28):

$$
y_{j}^{*}=x_{j} \exists+u_{1 j} \quad \text { latent equation }
$$

such that we only observe the binary outcome

$$
y_{j}^{\text {probit }}=\left(y_{j}^{*}>0\right) \quad \text { probit equation }
$$

The dependent variable for observation $j$ is observed only if

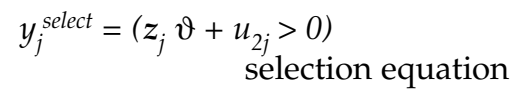

where: $u_{1 j} \sim \mathrm{N}(0,1)$

$u_{2 j} \sim \mathrm{N}(0,1)$

$$
\text { correlation }\left(\mathrm{u}_{2}, \mathrm{u}_{1}\right)=\Delta
$$

The identifying variables for the Heckman selection were the morbidity scale described in Table 1, the total number of ambulatory clinics per capita, and the total number of physicians per capita, at the municipality level. These variables are expected to influence the decision to seek and obtain health care services, and not, directly, the decision to use private versus public providers. In an alternate 
TABLE 2. Choice of health care provider by the elderly, using Heckman-probit regression with control for health care use, state of Rio Grande do Sul, Brazil, 1995

\begin{tabular}{|c|c|c|c|c|}
\hline & \multicolumn{2}{|c|}{ Health care use } & \multicolumn{2}{|c|}{ Provider choice } \\
\hline & $\begin{array}{l}\text { Marginal } \\
\text { effect }\end{array}$ & $\begin{array}{l}\text { Standard } \\
\text { error }\end{array}$ & $\begin{array}{c}\text { Marginal } \\
\text { effect }\end{array}$ & $\begin{array}{l}\text { Standard } \\
\text { error }\end{array}$ \\
\hline Individual income (log) & 0.002 & 0.003 & -0.004 & 0.006 \\
\hline Family income per capita (log) & $0.029^{a}$ & 0.008 & $0.123^{a}$ & 0.021 \\
\hline Morbidity scale & $0.068^{a}$ & 0.002 & NA & NA \\
\hline Total ambulatory clinics per capita & -0.077 & 0.058 & NA & NA \\
\hline Total physicians per capita & $0.006^{a}$ & 0.001 & NA & NA \\
\hline Public ambulatory clinics per capita & NA & NA & -0.113 & 0.153 \\
\hline Private physicians per capita & NA & NA & $-0.028^{b}$ & 0.013 \\
\hline Age & $0.003^{a}$ & 0.001 & $0.006^{a}$ & 0.001 \\
\hline Sex: male & $-0.043^{a}$ & 0.011 & -0.015 & 0.021 \\
\hline Race: nonwhite & $-0.030^{c}$ & 0.018 & $-0.131^{\mathrm{a}}$ & 0.037 \\
\hline \multicolumn{5}{|l|}{ Education } \\
\hline Primary & 0.011 & 0.015 & $0.149^{a}$ & 0.020 \\
\hline Secondary & 0.024 & 0.017 & $0.209^{a}$ & 0.039 \\
\hline University & $0.045^{c}$ & 0.024 & $0.321^{\mathrm{a}}$ & 0.065 \\
\hline Marital status: married & $0.025^{\mathrm{a}}$ & 0.007 & $0.050^{\mathrm{b}}$ & 0.024 \\
\hline Economic sector & -0.012 & 0.019 & $0.037^{b}$ & 0.017 \\
\hline Occupation & -0.019 & 0.013 & $-0.118^{a}$ & 0.018 \\
\hline Family size & 0.004 & 0.004 & $-0.012^{c}$ & 0.007 \\
\hline Imputed ${ }^{d}$ & 0.018 & 0.016 & $-0.028^{b}$ & 0.013 \\
\hline Probability of outcome & \multirow{2}{*}{\multicolumn{2}{|c|}{$\begin{array}{l}0.743 \\
7783\end{array}$}} & \multirow{2}{*}{\multicolumn{2}{|c|}{$\begin{array}{l}0.448 \\
5592\end{array}$}} \\
\hline Sample size & & & & \\
\hline
\end{tabular}

model, the morbidity scale was included as an additional explanatory variable for estimating the health input demand function. There were no important differences in the results with this alternate, which may be requested from the author if needed.

The health input under consideration - the choice of private versus public health care provider-is introduced in the production function as its expected probability. This two-stage procedure corrects for the endogeneity of the provider choice, since it is a choice variable within the model. Given the ordered nature of the self-assessed health variable, an ordered probit model was used in the health production function. A step in the sampling process was to divide the Rio Grande do Sul state into nine research regions. The same number of elderly was interviewed in each of the nine regions, which vary greatly in population size. Probability weights were introduced in all regressions in order to adjust for variations in population size among the nine regions, and thus provide results that more accurately portray the state-wide situation. The weight introduced was the inverse of the probability in fractional terms. In addition, to control for possible design-produced clustering, the nine regions were introduced in the regressions as clusters; specifically, adjusting the standard errors for intracluster correlation.

\section{RESULTS}

\section{Choice of health care providers}

Table 2 presents the results of the regression health care provider choice (probit equation), controlled for health care services utilization (Heckman selection equation). For the continuous independent variables, the marginal effects were calculated at their means. For the binary variables, the effects were calculated as the dis- crete change in the dependent variable from 0 to 1 .

The correlation between the health care services utilization and the provider choice equations is -0.020 . Based on a Wald test of independent equations, this correlation is not significantly different from $0\left(\mathrm{chi}^{2}(1)=0.02\right.$; probability $\left.>\mathrm{chi}^{2}=0.8756\right)$. The two equations are independent of each other, and the results would not be different if distinct, probit estimations were attempted. This is confirmed by the high correlation (0.995) between the predicted value of the private choice using a simple probit (estimation not shown here, but available from the author) and the predicted value using the probit with Heckman selection model. Likewise, no difference in the result for the health production function, shown below, is found if one or the other predicted value is used.

Two of the identifying variables in the selection equation were significant: 
TABLE 3. Impact of public health infrastructure on choice of public providers according to municipality size, by the elderly, state of Rio Grande do Sul, Brazil, 1995

\begin{tabular}{lcccc}
\hline Municipality size & $\begin{array}{c}\text { Sample } \\
\text { size }\end{array}$ & $\begin{array}{c}\text { Probability } \\
\text { of outcome }\end{array}$ & $\begin{array}{c}\text { Marginal } \\
\text { effect }\end{array}$ & $\begin{array}{c}\text { Standard } \\
\text { error }\end{array}$ \\
\hline Whole sample & 5592 & 0.452 & -0.113 & 0.153 \\
$<200$ 000 people & 3855 & 0.474 & -0.161 & 0.114 \\
$<100000$ people & 3188 & 0.490 & $-0.230^{\mathrm{a}}$ & 0.104 \\
$<50000$ people & 2195 & 0.522 & $-0.302^{\mathrm{b}}$ & 0.094 \\
\hline
\end{tabular}

a Significant at the $5 \%$ level.

${ }^{b}$ Significant at the $10 \%$ level.

(1) morbidity and (2) the total number of physicians, per capita, at the municipality level. These results show that the utilization of health care services is strongly based on need and is constrained by the local availability of physicians. On the other hand, the number of ambulatory clinics does not have an impact on health care utilization. Another point worth noticing is that even when a health care system, such as SUS, offers universal access at no cost, obtaining care is strongly constrained by household income.

For the most part, the results for the selection of a public versus a private provider provided in Table 2, agree with those of a previous study (29). One important result is that the proxies for the nonmonetary cost of a public provider and for the monetary cost a private provider have the expected impact. The elderly in municipalities with a greater number of public, ambulatory clinics are more likely to use public, rather than private providers, since the opportunity cost of a public provider is lower. The higher density of public clinics leads to lower transportation costs as well as less time and effort to obtain care. This impact should be particularly important to patients with higher ADL needs. This specific impact was not statistically significant in the results above, a point analyzed in more detail below. For the other proxy, where the cost of private physicians is higher (indicated by the number of private physicians per capita), the demand for private care is lower.

Observations with imputed values tend to rely more on the private sector than do observations without imputed values. The significance of this variable suggests that the use of imputed values might be underestimating the impact of the household income variable. Running the regressions without the imputed values (i.e., dropping the cases with missing data), the coefficients for the household income variable were slightly higher than when imputed values were used. This additional analysis is available from the author.

Elderly in municipalities with a greater number of public ambulatory clinics use more public providers. The statistical impact of this variable was not significant, suggesting that the municipality level is probably too broad a unit for analysis of public health facilities and that their impact needs to be studied at a subunit level. To check this possibility, simple probit regressions were run again on the choice of public versus private provider, restricting the sample to smaller and smaller municipalities.

Table 3 presents the results of the new regressions, which only included those who sought health care over the previous six months. Only the result for the "public ambulatory clinics per capita" variable are presented. This regression used the same independent variables as the regression above.

The impact of the number of public ambulatory clinics per capita variable is clearly related to municipality size. Especially in municipalities of fewer than 100000 people, the impact was very pronounced. An increase in one ambulatory clinic/1 000 people, decreased the probability of choosing a private provider by $47 \%(-0.230 / 0.490)$ in municipalities with less than 100000 people, and by $58 \%(-0.302$ / 0.522 ) in municipalities of less than 50000 . This basic measure of public health infrastructure has a significant impact on the selection of public health facilities in smaller municipalities and, probably, in neighborhoods within the larger municipalities.

\section{Health production function}

Table 4 presents the estimates for the health production function. Two alternative models are presented: one with, and one without, the morbidity scale. The McKelvey \& Zavoina's $R^{2}$ is presented because, based on simulations, it closely approximates the $\mathrm{R}^{2}$ obtained by fitting the linear regression model in the underlying latent variable (30). Using this interpretation, the model without morbidity was able to explain half the variability in the self-assessed health variable. The model with morbidity explained $80 \%$ of the variability in the dependent variable.

An important result was that the elderly who used a private provider had better self-assessed health status than those who used the public system. This result was not affected by the introduction of the morbidity scale. To facilitate interpretation, Table 5 presents the marginal effects of the probability of using private providers on each self-assessed health category. The marginal effects were calculated at the means of the continuous variables.

The use of private providers is associated with reductions in the probabilities of the elderly having worse, selfassessed health evaluations-very poor, poor, or fair-and increases in the probabilities of better health self evaluations-good or excellent. The impact-measured by dividing the marginal effect by the probability of the outcome-is stronger in the extreme categories. For instances, the reduction in the very poor category is larger than the reduction in the poor category, and the increase in the excellent category is larger than the increase 
TABLE 4. Results of ordered probit regression for the self-assessed health of the elderly in the state of Rio Grande do Sul, Brazil, 1995

\begin{tabular}{|c|c|c|c|c|}
\hline & \multicolumn{2}{|c|}{ Without morbidity } & \multicolumn{2}{|c|}{ With morbidity } \\
\hline & Coefficients & $\begin{array}{l}\text { Robust } \\
\text { errors }\end{array}$ & Coefficients & $\begin{array}{l}\text { Robust } \\
\text { errors }\end{array}$ \\
\hline Probability of private provider & $1.067^{\mathrm{a}}$ & 0.332 & $1.022^{\mathrm{a}}$ & 0.274 \\
\hline Age & $-0.005^{b}$ & 0.002 & $-0.005^{b}$ & 0.013 \\
\hline Sex: male & $0.290^{\mathrm{a}}$ & 0.028 & $0.122^{\mathrm{a}}$ & 0.032 \\
\hline Race: nonwhite & $0.120^{c}$ & 0.065 & $0.150^{\mathrm{b}}$ & 0.052 \\
\hline \multicolumn{5}{|l|}{ Education } \\
\hline Primary & 0.032 & 0.060 & -0.050 & 0.060 \\
\hline Secondary & $0.378^{a}$ & 0.100 & $0.219^{b}$ & 0.093 \\
\hline University & $0.574^{\mathrm{a}}$ & 0.164 & $0.446^{\mathrm{a}}$ & 0.155 \\
\hline Marital status: married & $-0.144^{a}$ & 0.034 & $-0.098^{a}$ & 0.038 \\
\hline Economic sector & $-0.203^{\mathrm{a}}$ & 0.032 & $-0.174^{\mathrm{a}}$ & 0.041 \\
\hline Occupation & 0.012 & 0.068 & 0.014 & 0.077 \\
\hline Morbidity & NA & NA & $-0.229^{a}$ & 0.007 \\
\hline Wald $\operatorname{chi}^{2}(8)$ & \multicolumn{2}{|c|}{$1184.98^{a}$} & \multicolumn{2}{|c|}{$927.79^{a}$} \\
\hline McFadden's R² & \multicolumn{2}{|c|}{0.032} & \multicolumn{2}{|c|}{0.105} \\
\hline McKelvey \& Zavoina's & \multicolumn{2}{|c|}{0.515} & \multicolumn{2}{|c|}{0.799} \\
\hline
\end{tabular}

a Significant at the $1 \%$ level.

${ }^{b}$ Significant at the $5 \%$ level.

c Significant at the $10 \%$ level.

TABLE 5. Marginal effects of the probability of using private providers by the elderly in the state of Rio Grande do Sul, Brazil, 1995

\begin{tabular}{lccccc}
\hline & \multicolumn{2}{c}{ Without morbidity } & & \multicolumn{2}{c}{ With morbidity } \\
\cline { 2 - 3 } Health category & $\begin{array}{c}\text { Probability } \\
\text { of outcome }\end{array}$ & $\begin{array}{c}\text { Marginal } \\
\text { effect }\end{array}$ & & $\begin{array}{c}\text { Probability } \\
\text { of outcome }\end{array}$ & $\begin{array}{c}\text { Marginal } \\
\text { effect }\end{array}$ \\
\hline Very poor & 0.078 & $-0.156^{\mathrm{a}}$ & & 0.057 & $-0.117^{\mathrm{a}}$ \\
Poor & 0.074 & $-0.095^{\mathrm{a}}$ & & 0.068 & $-0.093^{\mathrm{a}}$ \\
Fair & 0.0566 & $-0.110^{\mathrm{a}}$ & & 0.616 & $-0.120^{\mathrm{a}}$ \\
Good & 0.225 & $0.238^{\mathrm{a}}$ & & 0.220 & $0.245^{\mathrm{a}}$ \\
Excellent & 0.057 & $0.122^{\mathrm{a}}$ & & 0.039 & $0.086^{\mathrm{a}}$ \\
\hline
\end{tabular}

a Significant at the $1 \%$ level.

in the good category. The models with, and without, morbidity were not significantly different.

The use of expected probability in the health production function corrects for the endogeneity of the health inputs. Therefore, the poorer health outcomes can be attributed, within the constraints of the model, to the distinct experiences that patients have with the providers. One interpretation of this result is that the quality deficiencies (in the broadest sense) of the public sector are the reason for the poorer outcomes. However, since there were no specific indicators of quality of care in the dataset, the regression results are, at best, indirect indicators of these defi- ciencies, albeit reasonable, compelling, and supported by the literature. For instance, based on hospital mortality rates, services were found to be of lesser quality when provided by the public, as opposed to the private system (4); and public providers tended to have a lower level of specialization and technical capability (31).

There may be other possible explanations for the results, but the data available do not permit a comprehensive evaluation of their likelihood. For instance, it is possible that those survey participants who had recently paid for private care, were more likely to report good health. However, this "consumer satisfaction" possibility is unlikely in the present case because the survey asked how satisfied the participant was with the care received, and no significant difference resulted between those who had seen a public versus a private provider. Another possibility is that the recent use of the public or private system might be proxies for other health related issues, such as access to life-long medical care or healthier lifestyles. The large number of demographic variables considered in this study - sex, age, education, race, marital status, occupation, economic sector, as well as income and health infrastructure indicators-demonstrates that proper controls were used. It is unlikely that any significant, omitted factor was not related to these control variables. For instance, smoking and alcohol abuse are closely related to sex and education $(32,33)$. Nevertheless, a definite assessment of these possibilities must wait for replications of the study with different samples and methodology. Of particular benefit would be longitudinal studies of elderly health (unavailable at the regional or national level in Brazil) and more detailed information on health care services utilization.

\section{CONCLUSIONS}

\section{Public health system}

The results from the health care services utilization equation (Table 2) show that the total number (i.e., private and public) of physicians has an impact on health care utilization, but the number of ambulatory clinics does not. These results suggest that to improve access, the focus should be on increasing the number of primary care physicians, in both private and public practice, rather than on increasing the number of facilities. The results from the provider choice equation (Table 3) show that public health system utilization is constrained by the number of public ambulatory clinics. Therefore, it would follow that further investment in facilities would increase public system utilization and benefit households that cannot afford private care, espe- 
cially those with persons with higher ADL needs. Notice that the specific investment being recommended herepublic ambulatory units-is not expected to increase total health care utilization; instead, the benefit is increasing the use of public facilities, instead of private ones. Taking into account that, in Latin America, Brazil has the highest proportion of households with health expenditures at or above the "catastrophic" level (9) and the greatest number of households brought into poverty by health care expenses (34), increased utilization of the public health care system would be greatly beneficial to the population.

Results of the health production function (Table 4) show that public providers and poorer health outcomes are more often associated than are private providers. Given the number of demographic and other control variables used in the regressions, and the correction for the endogeneity of the health inputs, this result can be attributed to deficiencies within the public system, although competing interpretations have not been ruled out. Since the current research was restricted to the elderly, it is not possible to verify if these deficiencies are specific to the elderly or shared with other age groups. Although it is reasonable to expect that system-wide problems affect all ages, it is also likely that there are certain deficiencies that specifically impact the elderly.

\section{Policy recommendations}

In Brazil, the challenges facing SUS affect all the age groups, not just the elderly. The study results indicate that improvements can be made by further investing in health care infrastructure at the primary care level. The study did not allow for defining specific, investment recommendations; however, increased availability of primary health care physicians should increase health care services utilization, and additional public health care facilities should increase the use of public providers. Additionally, issues that may be discouraging use, such as poor management that produces long waiting times, may be present and should be studied and remedied.

The SUS public health care system needs to be reoriented toward the spe- cific health needs of the elderly population. As currently implemented, it does not meet these needs, especially in comparison to what the financiallyprivileged in Brazil can obtain from private providers. The first step is, therefore, a full implementation of the National Plan for Elderly Health, with all its components: raising the number and capabilities of the Resource Centers for Elderly Health; providing training on elderly health; supporting the Community Health and Family Health programs staff; and, perhaps most importantly, increasing the opportunity for an effective, geriatric consultation at the primary care level. Any significant improvement on these programs will bring measurable benefits.

A substantial challenge is to deliver the elements of the National Plan at the local level, especially in smaller municipalities where the needs are most acute, and the resources, most lacking. The long-term demographic trends indicate that emphasis on the specific needs of the elderly population should be a permanent feature of the Brazilian health system, and that of other Latin American countries as their populations age.

\section{REFERENCES}

1. Instituto Brasiliero de Geografia e Estatística. Projeção preliminar da população Brasileira por gênero e idade: 1980-2050. Rio de Janeiro: IBGE; 2000.

2. Pan American Health Organization. Health in the Americas. 2002 Edition. Washington, DC: PAHO; 2002.

3. Farias LO. Estratégias individuais de proteção à saúde: um estudo da adesão ao sistema de saúde suplementar. Cin \& Saude Colet. 2001; 6(2):405-16.

4. Gouvêa CSD, Travassos C, Fernandes C. Produção de serviços e qualidade da assistência hospitalar no Estado do Rio de Janeiro, Brasil,1992 a 1995. Rev Saude Publica. 1997; 31(6):601-17.

5. Chaimowicz F. A saúde dos idosos brasileiros às vésperas do século XXI: problemas, projeções e alternativas. Rev Saude Publica. 1997; 31(2):184-200.

6. Barros ALBL. Long-term care for elders in Brazil. J Nurs Scholarsh. 1999;31(2):135.

7. Ministério da Saúde. Redes estaduais de atenção à saúde do idoso: guia operacional e portarias relacionadas. Brasília: MS; 2002. Available from: http://dtr2001.saude.gov. br/bvs/publicacoes/redes_estaduais.pdf. Accessed 3 January 2005.

8. Silvestre JA, Costa Neto MM. Abordagem do idoso em programas de saúde da família. Cad Saude Publica. 2003;19(3):839-47.

9. Xu K, Evans DB, Kawabata K, Zeramdini R, Klavus J, Murray CJ. Household catastrophic health expenditure: a multicountry analysis. Lancet. 2003;362(9378):111-7.

10. Rosenzweig MR, Schultz TP. Estimating a household production function: heterogeneity, the demand for health inputs, and their effects on birth weight. J Polit Econ. 1983;91(5): $723-46$.

11. Schultz TP. Studying the impact of household economic and community variables on child mortality. Popul Dev Rev. 1984;10:215-35.

12. Kutty NK. The production of functionality by the elderly: a household production function approach. Appl Econ, 2000;32:1269-80.

13. Conselho Estadual do Idoso-Rio Grande do Sul. Os idosos do Rio Grande do Sul: estudo multidimensional de suas condições de vida. Porto Alegre: CEI; 1997.

14. Instituto Brasiliero de Geografia e Estatística. Pesquisa assistência médico-sanitária. Rio de Janeiro: IBGE; 1999.

15. Instituto Brasiliero de Geografia e Estatística. Pesquisa nacional por amostra de domicílios access and utilization of health services1998. Rio de Janeiro: IBGE; 2000.

16. Idler EL, Kasl SV, Lemke JH. Self-evaluated health and mortality among the elderly in New Haven, Connecticut, and Iowa and Washington Counties, Iowa, 1982-1986. Am J Epidemiol. 1990;13(1):91-103.

17. Idler EL, Benyamini Y. Self-rated health and mortality: a review of twenty-seven community studies. J Health Soc Behav. 1997; 38(1):21-37.

18. Crossley TF, Kennedy S. The reliability of selfassessed health status. J Health Econ. 2002;21 (4):643-58.

19. Benyamini $Y$, Leventhal EA, Leventhal H. Elderly people's ratings of the importance of 
health-related factors to their self-assessments of health. Soc Sci Med. 2003;56(8):1661-7.

20. Kerkhofs M, Lindeboom M. Subjective health measures and state dependent reporting errors. Health Econ. 1995;4:221-35.

21. Case A, Lubotsky D, Paxson C. Economic status and health in childhood: the origins of the gradient. Am Econ Rev. 2002;92(5):1308-34.

22. Souza ACT, Peterson KE, Andrade FM, Gardner J, Ascherio A. Circumstances of postneonatal deaths in Ceara, Northeast Brazil: mothers' health care-seeking behaviors during their infants' fatal illness. Soc Sci Med. 2000;51:1675-93

23. Gertler P, Locay L, Sanderson W. Are user fees regressive?: The welfare implications of health care financing proposals in Peru. J Econom. 1987;36(1-2): 67-88.

24. Sickles RC, Taubman P. Mortality and morbidity among adults and the elderly. In: Rosenzweig MR, Stark O, eds. Handbook of population and family economics. Volume 1A. New York: Elsevier; 1997. Pp. 559-643.

25. Briggs A, Clark T, Wolstenholme J, Clarke P. Missing... presumed at random: cost-analysis of incomplete data. Health Econ. 2003;12: 377-92.

26. Paulin GD, Ferraro DL. Do expenditures explain income? A study of variables for income imputation. J Econ Soc Meas. 1996;22:103-28.

27. Rubin DB. Multiple imputation after 18+ years. J Am Stat Assoc. 1996;91(434):473-89.

28. Van de Ven WPMM, Van Pragg BMS. The demand for deductibles in private health insurance: a probit model with sample selection. J Econom. 1981;17:229-52.

29. Bós AMG, Bós AJG. Determinantes na escolha entre atendimento de saúde privada e pública por idosos. Rev Saude Publica. 2004;38(1): $113-20$.

30. Long JS, Freese J. Regression models for categorical dependent variables using Stata. Revised edition. College Station: Stata Press; 2003.

31. Viacava F, Bahia L. Oferta de serviços de saúde: uma análise da pesquisa Assistência Médico-Sanitária (AMS) de 1999. Brasília: IPEA; 2002 (Discussion Paper 915)

32. Chaieb J, Castellarin C. Associação tabagismoalcoolismo: introdução às grandes dependên- cias humanas. Rev Saude Publica. 1998;32(3): 246-54.

33. Moreira LB, Fuchs FD, Moraes RS, Bredemeir $\mathrm{M}$, Cardozo S. Prevalência de tabagismo e fatores associados em área metropolitana da região Sul do Brasil. Rev Saude Publica. 1995; 29(1):46-51.

34. Murray CJL, Xu K, Evans DB, Kawabata K, Hanvoravongchai $\mathrm{P}$, Zeramdini $\mathrm{R}$, et al. Assessing the distribution of household financial contributions to the health system: concepts and empirical application. In: Murray CJL, Evans DB, eds. Health systems performance assessment: debates, methods and empiricism. World Health Organization: Geneva; 2003. Pp. 513-31.

Manuscript received on 26 January 2006. Revised version accepted for publication on 28 May 2007.

RESUMEN Objetivos. Las tendencias demográficas actuales subrayan la necesidad de comprender los retos de salud que enfrentan los adultos mayores de América Latina. En este estudio se examina si la selección del proveedor de atención sanitaria y los in-

Selección y utilización del proveedor de atención sanitaria por adultos mayores de un estado de Brasil: modelo estructural en Brasil.

Métodos. Se empleó un modelo estructural con una muestra tomada en 1995 en el sur de Brasil, para estimar los parámetros de una función que represente la selección del proveedor de atención sanitaria, controlada por la utilización de los servicios de salud y una función de producción de salud. La variable dependiente para la función de producción fue el autoinforme de salud. Estas dos funciones se relacionaron estructuralmente mediante la probabilidad de escoger un proveedor privado sobre uno público en la función de producción de salud, introducida como variable explicativa adicional. Con este vínculo estructural, la función de producción estableció en qué grado influyó en el estado de salud la selección de un proveedor privado frente a uno público, controlado por la posibilidad de que las personas con peor salud tengan la tendencia de preferir uno u otro tipo de proveedor de atención sanitaria.

Resultados. La utilización de los servicios de salud por parte de los adultos mayores se vio limitada por dos factores: el número de proveedores en el municipio y los ingresos del hogar. Los adultos mayores que viven en municipios con un mayor número de proveedores y clínicas ambulatorias públicos mostraron una mayor probabilidad de utilizar el sistema público. Los pacientes que utilizaron el sistema público de atención sanitaria consideraron peor su estado de salud que los que utilizaron el sistema privado. Este resultado no varió después de controlar por las variables demográficas y la morbilidad.

Conclusiones. El sistema público de salud de Brasil no responde adecuadamente a las necesidades de salud de los adultos mayores. Entre las recomendaciones de políticas se encuentran invertir más en la infraestructura de los servicios públicos de salud, implementar el Plan Nacional para la Salud de los Adultos Mayores en su totalidad y desarrollar nuevos programas para lograr consultas geriátricas eficacientes en el nivel primario de salud.

Palabras clave

Servicios de salud para ancianos, transición de salud, práctica de salud pública, geriatría, Brasil. 